\title{
Conjugated Linoleic Acid (CLA) Effect on Body Weight and Body Composition in Women (Systematic Review and Meta-Analysis).
}

\begin{abstract}
Introduction: Conjugated linoleic acid (CLA) is a food supplement that is proposed as an anti-obesity supplement in animal and human studies. Animal studies have shown a significant anti-obesity effect of CLA, but results in humans were inconsistent, where some of the studies found an anti-obesity effect while other studies failed to find any decline in obesity markers after CLA supplementation. This meta-analysis aimed to determine if oral CLA supplementation has been shown to reduce obesity-related markers in women.
\end{abstract}

Method: Pub Med, Cochrane Library, and Google Scholar were used to identify the eligible trials using two main searching strategies: the first one was to search eligible trials using keywords "Conjugated linoleic acid", "CLA", "Women", and the second strategy was to extract the eligible trials from previously published systematic reviews and meta-analyses. The eligible trials were placebo control trials where women supplemented with CLA mixture in the form of oral capsules for 6 months or less. Furthermore, eligible trials reported body weight $(\mathrm{BW})$, body mass index (BMI), total body fat (TBF), percentage body fat (BF\%), and/ or lean body mass (LBM). The quality of each included study was assessed using both JADAD scale and an adapted CONSERT checklist.

Results: Meta-analysis of 8 eligible trials showed that CLA supplementation was significantly associated with reduced BW (Mean \pm $\mathrm{SD}, 1.2 \pm 0.26 \mathrm{~kg}, \mathrm{p}<0.001)$, BMI $\left(0.6 \pm 0.13 \mathrm{~kg} / \mathrm{m}^{2}, \mathrm{p}<0.001\right)$ and TBF $(0.76 \pm 0.26 \mathrm{~kg}, \mathrm{p}=0.003)$ in women, when supplemented over 6-16 weeks. Subgroup meta-analysis demonstrated a significant reduction in BW $(1.29 \pm 0.31 \mathrm{~kg}, \mathrm{p}<0.001), \mathrm{BMI}(0.60 \pm$ $\left.0.14 \mathrm{~kg} / \mathrm{m}^{2}, \mathrm{p}<0.001\right)$ and TBF $(0.82 \pm 0.28 \mathrm{~kg}, \mathrm{p}=0.003)$ in the trials that had recruited overweight-obese women. The second subgroup meta-analysis, that considered the menopausal status of the participants, found that CLA was significantly associated with reduced $\mathrm{BW}(1.35 \pm 0.37 \mathrm{~kg}, \mathrm{p}<0.001 ; 1.05 \pm 0.36 \mathrm{~kg}, \mathrm{p}=0.003)$ and $\mathrm{BMI}\left(0.50 \pm 0.17 \mathrm{~kg} / \mathrm{m}^{2}, \mathrm{p}=0.003 ; 0.75 \pm 0.2 \mathrm{~kg} / \mathrm{m}^{2}, \mathrm{p}<\right.$ $0.001)$ in both pre and post-menopausal age women, respectively. A reduction in TBF $(1.09 \pm 0.37 \mathrm{~kg}, \mathrm{p}=0.003)$ was only significant in post-menopausal women.

Discussion: This meta-analysis suggests a moderate anti-obesity effect of CLA on BW, BMI and TBF reduction in women, when supplemented over 6-16 weeks, particularly in overweight-obese women and post-menopausal women. More well-designed trials are required to confirm this meta-analysis results.

\section{Conflict of Interest}

There is no conflict of interest 